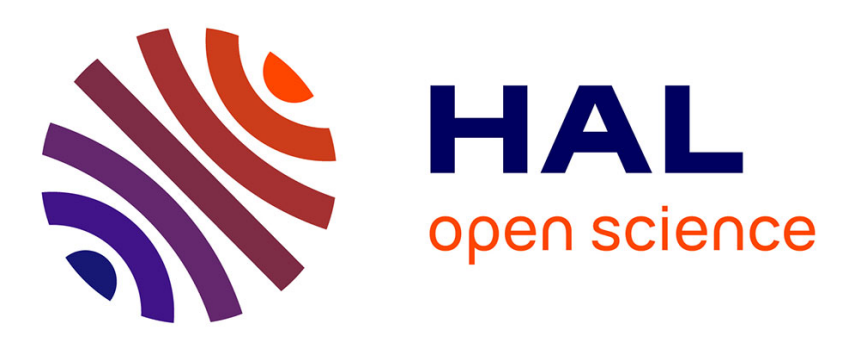

\title{
For and Against: Perceived Entitativity of Supportive and Oppositional Opinion Groups
}

Françoise Askevis-Leherpeux

\section{To cite this version:}

Françoise Askevis-Leherpeux. For and Against: Perceived Entitativity of Supportive and Oppositional Opinion Groups. Group Processes and Intergroup Relations, 2005, 8 (1), pp.27-37. 10.1177/1368430205048617 . hal-00571592

\section{HAL Id: hal-00571592 \\ https://hal.science/hal-00571592}

Submitted on 1 Mar 2011

HAL is a multi-disciplinary open access archive for the deposit and dissemination of scientific research documents, whether they are published or not. The documents may come from teaching and research institutions in France or abroad, or from public or private research centers.
L'archive ouverte pluridisciplinaire HAL, est destinée au dépôt et à la diffusion de documents scientifiques de niveau recherche, publiés ou non, émanant des établissements d'enseignement et de recherche français ou étrangers, des laboratoires publics ou privés. 


\title{
For and Against: Perceived Entitativity of Supportive and Oppositional Opinion Groups
}

\author{
Françoise Askevis-Leherpeux \\ University of Paris 5
}

\begin{abstract}
It is argued that self-labeling of opinion groups as holding 'for' or 'against' attitudes influences perceived entitativity of such groups. Based on literature on positivity biases and Moscovici's analysis of social change (1976), we predicted that individuals may associate support with nomicity, and should perceive supportive groups as more entitative than oppositional ones. In three studies, participants rated the entitativity of supportive and oppositional groups varying in extremity and homogeneity. The first two studies showed that support was associated with greater entitativity than opposition, but only in the case of extreme opinions. They also replicated past findings that extremity and homogeneity increase perceived entitativity. A third study showed that activating an intergroup context did not lead to an ingroup-outgroup effect, but suggested that the joint effects of favorability and extremity depend on how well-defined opinions the groups are supposed to have.
\end{abstract}

KEYWORDS lay theories of groups, opinion groups, perceived entitativity

THE DEFINITION of a group was initially based on interaction. But, by the end of the 1960s, the decline of small-group research, followed by the increasing influence of social cognition, led to the use of the term 'group' in the same manner as 'social category' (Oberlé, 1996; Steiner, 1974). Nowadays, while some authors still defend the definition as one restricted to interacting small groups, others suggest conceptualizing a group as being either dynamic, categorical, or both (Wilder \& Simon, 1998).

The question was recently extended to the perspective of lay persons (Hong, Levy, \& Chiu,
2001). Most lay theories of groups refer to the concept of entitativity, defined by Campbell (1958) as the degree to which a collection of individuals is perceived as having "the nature of

\section{Author's note}

Address correspondence to Françoise Askevis-Leherpeux, Laboratoire 'Temps, Emotion, et Cognition', U.F.R. de Psychologie Université Charles de Gaulle - Lille III, B.P. 149, 59653 Villeneuve d'Ascq Cedex, France [email: askevis-leherpeux@univ-lille3.fr] 
an entity, (as) having real existence' (p. 17). It appears that people do not perceive only two types of groups (dynamic vs. categorical ones), but a larger set of groups ranging from aggregates (e.g. loose associations, such as people in a line at the bank) to high entitative groups (e.g. intimacy groups, such as friends or family) (Lickel et al., 2000; Lickel, Hamilton, \& Sherman, 2001)

In line with the Gestalt principles of perceptual organization, Campbell argued that the perceived entitativity of a group increases as a function of its units' structural properties, namely their common fate, followed by their similarity on relevant dimensions and their physical proximity. These criteria contribute to provide a group with clear and impermeable boundaries, which, in turn, heightens differentiation from other groups. Later, it was suggested that perceived entitativity not only increases as a function of other structural properties, including interdependence and extremity (Lickel et al., 2000; McGarty, Haslam, Hutchinson, \& Grace, 1995; Mullen, 1991), but also depends on group membership. Some authors, referring to literature on the representation of groups in memory, hypothesize that ingroups, because of their greater perceived heterogeneity, should be perceived as less entitative than outgroups (Mullen, 1991). Others, emphasizing that ingroup members are interdependent and share common heritage and common goals, suggest that ingroups, despite their greater perceived heterogeneity, should be perceived as more entitative than outgroups (Brewer \& Harasty, 1996; Hamilton \& Sherman, 1996; Sherman, Hamilton, \& Lewis, 2000).

At the same time, some authors analyzed the consequences of perceived entitativity. For instance, it has been shown that the perception of a group as an entity leads to more polarized trait judgments (Dasgupta, Banaji, \& Abelson, 1999; Morchain \& Schadron, 1999; Susskind, Maurer, Thakkar, Hamilton, \& Sherman, 1999), increases the extent to which group membership entails collective responsibility (Lickel et al., 2001), and contributes to decrease its credibility and its persuasive influence (Harkins \& Petty, 1987; Wilder, 1977, 1990).
Hypotheses on antecedents and consequences were mostly tested by using social categories as groups. Other kinds of groups were neglected, especially opinion groups, that is, groups of people who overall share a same attitude toward a societal issue. These groups have an important place in our social environment: we learn about them from the media, they often try to mobilize our support, we discuss them with peers, we feel more or less close to them, and so on. Moreover, their perceived entitativity may have relevant societal consequences. For instance, literature on consequences of perceived entitativity suggests that the more an opinion group is perceived as entitative, the more it will be rated in an extreme way and the less it will be credible and influential.

Opinion groups vary in their selfpresentation as being 'for' or 'against' a specific issue. Most groups define themselves in terms of either support (e.g. for the rights of the child, for gender parity in politics, or for euthanasia), or opposition (e.g. against death penalty, against nuclear power, or against globalization). Some political movements, such as the French extreme right party 'Front National', use both 'for' and 'against' arguments to defend an idea (e.g. both 'for the national preference' and 'against migrants'). It also happens that opposite movements, supporting and opposing the same issue, define themselves as 'pro' groups. For instance, American social movements that support and oppose abortion define themselves as supportive ('pro-choice' and 'prolife'). This suggests that using a 'for' or an 'against' label does not only reflect the position of an opinion group, but may also have strong consequences on its perception.

As far as we know, social psychology did not address this question directly. But, one may infer a hypothesis from two different lines of research. First, research on positivity biases and attribution showed that favorability is generally perceived as normative, and that disagreement is associated with norm-discrepancy (e.g. Hamilton \& Zanna, 1972; Skowronski \& Carlston, 1989). Second, in his analysis of social change, Moscovici (1976) made a distinction 
between nomic groups and anomic groups, 'according to whether or not they possess a common code, a recognized norm, a dominant response, or an identified consensus' (p. 75). He argued that this distinction holds for majorities as well as minorities, and is independent of groups' numerical status. Based on the fact that defining features of nomicity also contribute to perceived entitativity (Hamilton \& Sherman, 1996), and that normativity implies nomicity, one can predict that supportive groups should be perceived as more entitative than oppositional ones. This would confirm that perceived entitativity of social groups does not only depend on their structural properties (extremity and homogeneity), but also on the context in which these properties are activated.

In order to test this hypothesis, we used a paradigm based on a study by McGarty and colleagues (1995), who confirmed that perceived entitativity of an opinion group increases as a function of the extremity of its mean position and of intragroup homogeneity, but used only oppositional groups. Their paradigm involved the presentation of a series of graphic stimuli representing positions of the members of a single group on bipolar content-free attitude scales, which allows one to test the effects of groups' structural properties (extremity and homogeneity) independently of issues and of participants' own attitudes.

We ran three studies, where we presented positions of members of hypothetical groups that varied not only in extremity (the group's mean position was moderate or extreme) and homogeneity (within-group agreement was low or high), but also in favorability (the group's mean position was 'for' or 'against'). While the first two studies did not mention the target group's membership, the third one examined the joint effects of favorability, extremity, and homogeneity, in a comparative intergroup context.

We formulated three sets of hypotheses:

1. Supportive groups should be perceived as more entitative than oppositional ones.

2. Extremity and homogeneity should increase perceived entitativity.
3. Ingroup, if perceived differently from the outgroup, should be associated with higher entitativity than outgroup.

\section{Study 1}

\section{Method}

Stimulus materials Participants were presented with a series of eight graphic stimuli. They were told that each stimulus represented the positions of the members of a single group on a bipolar attitude scale ranging from -5 (complete opposition) to +5 (complete support). Because McGarty et al. (1995) found that extremity only increased entitativity for large groups, that is for 12-member groups as compared with 8 and 4 , every group included 12 members.

The eight groups to be judged varied in favorability, extremity, and homogeneity (see Figure 1).

Group mean attitude reflected either support or opposition (favorability), and was either extreme or moderate (extremity). The mean of the distribution was thus either extremely negative (approximately -3 ), moderately negative (approximately -1 ), moderately positive (approximately +1 ), or extremely positive (approximately +3 ). Moreover, in order to make homogeneity distinct from the number of discrete positions occupied by the members of the group (diversity), homogeneity was operationalized as intraclass contiguity. The distributions included either two adjacent unoccupied positions in the middle of the group (low homogeneity, or high variability), or did not include any discontinuity (high homogeneity, or low variability).

Finally, in order to decrease the salience of manipulations, the form of the distribution was either symmetrical or left-skewed or rightskewed, and the form was randomized across stimuli. ${ }^{1}$

Participants and design Fifty-six undergraduate students (53 women and 3 men) enrolled in introductory psychology classes at the University of Paris 5 (France) took part in the study (mean age $=21.6$ years). The study was based on a 2 


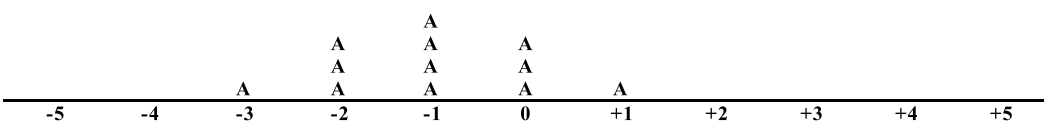

1a- A high homogeneous and moderately oppositional group $(M=-1 ; S D=1.13)$

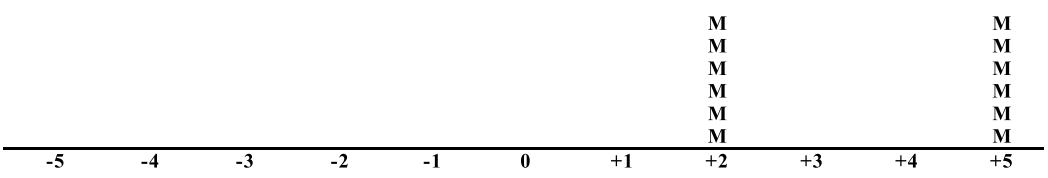

1b- A low homogeneous and extremely supportive group $(M=+3.5, S D=1.57)$

Figure 1. Two examples of groups (symmetrical distributions).

(favorability: for vs. against) $\times 2$ (extremity: extreme vs. moderate) $\times 2$ (homogeneity: high vs. low) within-participants design.

Procedure Participants were tested in classroom settings of up to 15 students. They were told that the present study was concerned with attitudes, and were given a questionnaire. The first page explained what an attitude was, and how a numerical attitude scale worked. Additionally, in order to prevent participants from confounding group mean position with a general attitudinal orientation, two examples were provided to illustrate that holding antiopinions (e.g. against de-penalizing 'soft' drugs such as hashish, or against giving firearms to municipal policemen) reflect different, and even opposite, overall attitudes. Finally, participants were told that they would be presented with a series of scales measuring the attitudes of the members of different groups, labeled by random letters. They were told that the content of the attitude was unspecified, and that they would have to judge those groups by taking into account how the members had assigned themselves on the scale.

Subsequent pages were presented to the eight groups, in a random order.

After every stimulus, participants were asked to assess group entitativity, by rating on a 7point scale the extent to which they perceived the group as a 'unity', a 'coherent whole' $(1=$ not at all, $7=$ totally). Finally, participants were debriefed and thanked for their participation.

\section{Results}

The data were submitted to a 2 (favorability) $\times 2$ (extremity) $\times 2$ (homogeneity) withinparticipants analysis of variance. The means and standard deviations of perceived entitativity are reported in Table 1.

The results showed main effects of the three factors. Supportive groups were perceived as more entitative $(M=3.86)$ than oppositional ones $(M=3.63)\left(F(1,55)=5.58, p<.05, \eta^{2}=\right.$ $.09)$. Extremity $(M=4.25$ vs. $M=3.22 ; F(1,55)$ $\left.=59.63, p<.001, \eta^{2}=.52\right)$, and homogeneity $(M$ $=4.16$ vs. $M=3.32 ; F(1,56)=20.27, p<.001$, $\left.\eta^{2}=.27\right)$, increased perceived entitativity.

The analysis also revealed unpredicted interactions between favorability and extremity $\left(F(1,55)=21.89, p<.001, \eta^{2}=.28\right)$, and between homogeneity and extremity $(F(1,55)=$ $\left.7.30, p<.01, \eta^{2}=.11\right)$. Post hoc analyses (LSD tests) showed that supportive groups were rated as more entitative only if extreme in their attitudes $\left(p<.001, \eta^{2}=.24\right.$ vs. $\left.p=.16, \eta^{2}=.04\right)$. The second interaction revealed that the homogeneity effect was less pronounced for extreme groups $\left(p<.001, \eta^{2}=.11\right)$, than for moderate ones $\left(p<.001, \eta^{2}=.32\right)$, or, inversely, that ratings of high homogeneous groups were less sensitive to information about extremity $(p<$ $\left..001, \eta^{2}=.25\right)$ than low homogeneous ones $\left(p<.001, \eta^{2}=.53\right)$. 
Table 1. Mean scores (and standard deviations) of groups' perceived entitativity as a function of favorability, extremity, and homogeneity (Study 1 )

\begin{tabular}{|c|c|c|c|c|c|c|c|c|}
\hline \multirow[b]{3}{*}{ Homogeneity } & \multicolumn{4}{|c|}{ Opposition } & \multicolumn{4}{|c|}{ Support } \\
\hline & \multicolumn{2}{|c|}{ Extreme } & \multicolumn{2}{|c|}{ Moderate } & \multicolumn{2}{|c|}{ Extreme } & \multicolumn{2}{|c|}{ Moderate } \\
\hline & $M$ & $S D$ & $M$ & $S D$ & $M$ & $S D$ & $M$ & $S D$ \\
\hline High & 4.30 & 1.46 & 3.86 & 1.36 & 4.75 & 1.41 & 3.73 & 1.43 \\
\hline Low & 3.57 & 1.48 & 2.77 & 1.28 & 4.39 & 1.33 & 2.55 & 1.24 \\
\hline Mean & 3.94 & & 3.31 & & 4.57 & & 3.14 & \\
\hline
\end{tabular}

\section{Conclusion}

The first study demonstrated the role of favorability in perceived entitativity, but showed that its effect was qualified by an interaction with extremity. Supportive groups were associated with higher entitativity only if extreme in their attitudes.

The study also confirmed the role of extremity and homogeneity, and showed that homogeneity had a weaker effect for extreme than for moderate groups.

Nonetheless, because of the numerical nature of the attitude scale, one may argue that the role of favorability, even if qualified by an interaction with extremity, is a matter of evaluative connotation of the numbers associated with attitude (positive vs. negative), rather than attitude itself (for vs. against). In fact, even if participants were prevented from confounding positions on an attitude scale with a general orientation, they may have used the positive end of the scale as an anchor point (Sherif \& Sherif, 1967; Skowronski \& Carlston, 1989), and associated negative numbers with some essentially undesirable quality. In order to examine this possibility, we replicated the first study by using explicit verbal labels on the scale.

\section{Study 2}

\section{Method}

Fifty-five undergraduate students (49 women and 6 men) enrolled in introductory psychology classes at the University of Paris 5 (France) took part in the study (mean age $=20.6$ years) The same design and the same procedure as in Study 1 were used, except for the attitude scale, which was based on verbal statements instead of numerical values, and ranged from 'complete opposition' to 'complete support'.

\section{Results}

Mean results (and standard deviations) are presented in Table 2. Data displayed the same pattern as in Study 1, and showed main effects of favorability, extremity, and homogeneity. Supportive groups were perceived as more entitative $(M=3.94)$ than oppositional ones $(M=3.68)\left(F(1,54)=6.43, p<.05, \eta^{2}=.11\right)$. Extreme groups were perceived as more entitative $(M=4.42)$ than moderate groups $(M=3.20)\left(F(1,54)=92.73, p<.001, \eta^{2}=.63\right)$, and high homogeneity was associated with greater entitativity $(M=4.62)$ than low homogeneity $(M=2.99)(F(1,54)=118.3, p<.001$, $\left.\eta^{2}=.69\right)$.

Moreover, these main effects were qualified by the same interactions between favorability and extremity $\left(F(1,54)=17.22, p<.001, \eta^{2}=\right.$ $.24)$, and between homogeneity and extremity $\left(F(1,54)=13.37, p<.001, \eta^{2}=.20\right)$. As in Study 1 , post hoc-analyses showed that supportive groups were rated as more entitative only if extreme in their attitudes $\left(p<.001, \eta^{2}=.28\right.$ vs. $\left.p=.48, \eta^{2}=.007\right)$, and that the effect of homogeneity was less pronounced for extreme $(p<$ $\left..001, \eta^{2}=.53\right)$ than for moderate groups $\left(p<.001, \eta^{2}=.70\right)$, or inversely. 
Table 2. Mean scores (and standard deviations) of groups' perceived entitativity as a function of favorability, extremity, and homogeneity (Study 2; verbal scale)

\begin{tabular}{|c|c|c|c|c|c|c|c|c|}
\hline \multirow[b]{3}{*}{ Homogeneity } & \multicolumn{4}{|c|}{ Opposition } & \multicolumn{4}{|c|}{ Support } \\
\hline & \multicolumn{2}{|c|}{ Extreme } & \multicolumn{2}{|c|}{ Moderate } & \multicolumn{2}{|c|}{ Extreme } & \multicolumn{2}{|c|}{ Moderate } \\
\hline & $M$ & $S D$ & $M$ & $S D$ & $M$ & $S D$ & $M$ & $S D$ \\
\hline High & 4.84 & 1.24 & 4.25 & 1.31 & 5.33 & 1.01 & 4.07 & 1.18 \\
\hline Low & 3.40 & 1.28 & 2.24 & 0.98 & 4.11 & 1.37 & 2.25 & 1.06 \\
\hline Mean & 4.12 & & 3.24 & & 4.72 & & 3.16 & \\
\hline
\end{tabular}

\section{Conclusion}

Study 2 ruled out the possibility that asymmetry between 'for' and 'against' might have been due to the labeling of the scale.

Taken together, both studies showed that supportive groups were rated as more entitative than oppositional ones, but only if extreme in their attitude. They also documented the role of extremity and homogeneity, and showed that the homogeneity effect was less pronounced for extreme groups than for moderate ones.

When considering groups' mean position on the scale, the overall pattern of data suggests that participants did not perceive four types of opinion groups, but only three: extremely supportive groups (highest in perceived entitativity), extremely oppositional groups, and either supportive or oppositional moderate groups (lowest in perceived entitativity). Support would be associated with greater nomicity than opposition only in case of extremity. While perception of extreme groups would depend on both favorability and homogeneity, perception of moderate groups would depend only on homogeneity.

But this interpretation does not take into account the fact that participants may be members of the groups to be judged. This is why Study 3 included the three factors identified above in an explicit intergroup context, specifying the groups but not the issue.

\section{Study 3}

The aim of this study was to replicate the first one in an intergroup context by using a full ingroup-outgroup between-participants design. It was expected that the ingroup, if perceived differently from the outgroup, should be associated with higher entitativity than the outgroup.

\section{Method}

Design and participants The study was based on a 2 (favorability: for vs. against) $\times 2$ (extremity: extreme vs. moderate) $\times 2$ (homogeneity: high vs. low) $\times 2$ (perceiver group: psychology vs. law students) $\times 2$ (target group: psychology vs. law students) design, with the last two variables as between-participants factors. Psychology $(n=101)$ and law $(n=97)$ undergraduate students of the University of Paris 5 (France) took part in the study (156 women and 42 men; mean age $=21.4$ years $)$. These two groups of students shared the same campus, had mutual negative stereotypes, ${ }^{2}$ and, as confirmed by a post-test, displayed an outgroup homogeneity effect. ${ }^{3}$ They were told that a survey about several societal issues had been conducted on the campus, and were randomly informed that all of the eight groups to be judged were composed of psychology or law students who had participated in the survey. In all other ways, the study was an exact replication of Study 1 and did not mention the issue under judgment. 
Table 3. Mean scores (and standard deviations) of groups' perceived entitativity as a function of target group, favorability, extremity, and homogeneity (Study 3)

\begin{tabular}{|c|c|c|c|c|c|c|c|c|c|}
\hline \multirow{3}{*}{$\begin{array}{l}\text { Target } \\
\text { group }\end{array}$} & \multirow[b]{3}{*}{ Homogeneity } & \multicolumn{4}{|c|}{ Opposition } & \multicolumn{4}{|c|}{ Support } \\
\hline & & \multicolumn{2}{|c|}{ Extreme } & \multicolumn{2}{|c|}{ Moderate } & \multicolumn{2}{|c|}{ Extreme } & \multicolumn{2}{|c|}{ Moderate } \\
\hline & & $M$ & $S D$ & $M$ & $S D$ & $M$ & $S D$ & $M$ & $S D$ \\
\hline \multirow[t]{2}{*}{ Psychology } & High & 4.76 & 1.64 & 4.14 & 1.42 & 5.28 & 1.06 & 4.28 & 1.23 \\
\hline & Low & 3.33 & 1.66 & 2.48 & 1.24 & 4.07 & 1.54 & 2.83 & 1.46 \\
\hline Mean & & 4.04 & & 3.31 & & 4.67 & & 3.55 & \\
\hline \multirow[t]{2}{*}{ Law } & High & 4.65 & 1.54 & 4.02 & 1.56 & 4.89 & 1.43 & 4.24 & 1.56 \\
\hline & Low & 3.37 & 1.57 & 2.64 & 1.31 & 4.21 & 1.56 & 2.46 & 1.23 \\
\hline Mean & & 4.01 & & 3.33 & & 4.55 & & 3.35 & \\
\hline Overall mean & & 4.02 & & 3.32 & & 4.61 & & 3.45 & \\
\hline
\end{tabular}

\section{Results}

Data did not reveal any interaction between perceiver and target groups $(F(1,194)<1)$, indicating that the activation of an intergroup context did not lead to an ingroup-outgroup effect. Nevertheless, an interaction between perceiver group and homogeneity emerged $\left(F(1,194)=10.88, p<.001, \eta^{2}=.05\right)$, revealing that psychology students were more sensitive to information about homogeneity $(M=4.63$ vs. $M=3.00 ;\left(F(1,99)=210.84, p<.001, \eta^{2}=.68\right)$ than law students $(M=4.42$ vs. $M=3.34 ; F(1,95)$ $\left.=73.15, \eta^{2}=.44\right)$. Perceiver group did not have any other effect.

Table 3 presents the mean ratings (and standard deviations) of entitativity as a function of target group, favorability, extremity, and homogeneity.

As in previous studies, supportive groups were associated with greater entitativity $(M=$ 4.02) than oppositional ones $(M=3.68)$ $\left(F(1,194)=28.30, p<.001, \eta^{2}=.13\right)$. Extreme groups were perceived as more entitative $(M=$ 4.32) than moderate groups $(M=3.38)$ $\left(F(1,194)=189.99, p<.001, \eta^{2}=67\right)$. High homogeneous groups were perceived as more entitative $(M=4.53)$ than low homogeneous ones $(M=3.17)\left(F(1,194)=258.64, p<.001, \eta^{2}\right.$ $=.57)$.

These main effects were qualified by the same interactions between favorability and extremity $\left(F(1,194)=14.47, p<.001, \eta^{2}=.07\right)$ and between homogeneity and extremity $\left(F(1,194)=9.61, p<.01 \eta^{2}=.05\right)$. But, results revealed an interaction between the three factors $\left(F(1,194)=6.41, p<.05, \eta^{2}=.03\right)$. Post hoc analyses showed that interaction between favorability and extremity was significant only when the target group was a low homogeneous group $\left(p<.001, \eta^{2}=.09\right.$ vs. $\left.p=.11, \eta^{2}=.01\right)$. Finally, this last interaction was qualified by an interaction with group target, and was significant only when the low homogeneous group was composed of law students $\left(p<.001, \eta^{2}=.21\right.$ vs. $\left.p=.14, \eta^{2}=.02\right)$. In that case, support was associated with higher entitativity only in the case of extremity. In all other cases, favorability and extremity had additive effects.

\section{Conclusion}

This study replicated the first one in an intergroup context, by asking psychology and law students to rate perceived entitativity of either psychology or law student opinion groups, which varied in terms of favorability, homogeneity, and extremity.

Results did not reveal an ingroup-outgroup effect. This may be due to the fact that the paradigm was simply too 'minimal', and not explicitly comparative enough, to make participants sensitive to ingroup-outgroup target 
membership and to lead them to identify with their own group (Brewer \& Harasty, 1996).

Nevertheless, the effect of homogeneity depended on perceiver group membership. Psychology students were more sensitive to information about homogeneity than law students. One interpretation should refer to the fact that the proportion of females was higher among psychology students (.89) than among law students $(.68)\left(\chi^{2}(1)=13.14, p<\right.$ $.001)$. Literature on sex differences in influenceability and conformity suggests that women are more aversive toward interpersonal disagreement than men (Eagly \& Carli, 1981; Maslach, Santee, \& Wade, 1987; Mucci-Faïna, 1996). Even if, in this experiment, disagreement did not directly involve participants, we examined whether the difference between the two samples could not be (at least partially) explained in terms of gender. ${ }^{4}$ Because the proportion of males among psychology students was very low, only law student data were analysed as a function of gender. There was no effect of gender, and no interaction implying gender, which suggests that the difference between psychology and law students is not due to a sampling bias. Another interpretation should be that psychology students are required to take statistics courses and/or associate psychology with analysis of interindividual differences.

Analysis of data as a function of favorability, extremity, and homogeneity led to the same overall pattern as in previous studies. Homogeneity and extremity increased perceived entitativity, and favorability was a cue for perceived entitativity only when the groups hold extreme attitudes. But, the effect size of interaction between favorability and extremity was higher for low homogeneous groups composed of law students. This difference between the two target groups may be due to the fact that they are not associated with similar expectations. Compared with French psychology students, French law students are known to have 'well-defined', and even conservative and extremist, opinions. Thus, they should be perceived as a nomic population, with a common code and a recognized norm.
It suggests that, when information about homogeneity is inconsistent with expectations about nomicity, information processing leads to examining favorability and extremity as interdependent cues. In contrast, when information about homogeneity does not disconfirm expectations, information processing is less complex, and favorability and extremity are processed as additive cues for perceived entitativity.

\section{General discussion}

The aim of the three studies presented in this paper was to examine perceived entitativity of opinion groups as a function of the favorability of their mean position (for vs. against), and to confirm the role of extremity, and homogeneity. All three studies were based on a minimal paradigm adapted from McGarty and colleagues (1995), using content-free attitudinal dimensions ranging from opposition to support. The first two studies did not specify the groups under judgment, and varied only by the numerical versus verbal labeling of the attitudinal scale. The third one activated an explicit intergroup context, by asking psychology and law students to rate perceived entitativity of opinion groups composed of either psychology or law students.

We predicted first that favorability should be an important cue for opinion groups' perceived entitativity. In line with literature on positivity biases and with Moscovici's analysis of normativity and nomicity, we predicted that supportive groups should be perceived as more entitative than oppositional ones.

A second set of hypotheses, based on previous literature on perceived entitativity and intergroup differentiation, stated that extremity and homogeneity should increase perceived entitativity.

Finally, we predicted that ingroup, if perceived differently from outgroup, should be associated with greater entitativity than outgroup.

Results of the three studies converge on the conclusion that supportive groups were perceived as more entitative that oppositional ones, but only if extreme in their attitudes. 
Comparison between Study 1 and Study 2 showed that asymmetry between 'for' and 'against' did not depend on the labeling of the scale. The three studies also confirmed hypotheses about the role of homogeneity and extremity, but showed that the homogeneity effect was less pronounced for extreme than for moderate groups.

The effect of favorability, and its interaction with extremity, suggest that naive theories about support versus opposition are close to Moscovici's analysis of normativity and nomicity (1976). But, support appears to be associated with greater nomicity than opposition only in the case of extremity. Individuals did not perceive four types of opinion groups, but only three: extremely supportive groups (highest in perceived entitativity), extremely oppositional groups, and either supportive or oppositional moderate groups (lowest in perceived entitativity). While perception of extreme groups would depend on both favorability and homogeneity, perception of moderate groups would depend mostly on their homogeneity.

Activating an intergroup context (Study 3) did not lead to any ingroup-outgroup effect. Knowing that groups under consideration have mutual negative stereotypes and display an outgroup homogeneity effect, it confirms that greater homogeneity does not necessarily lead to greater perceived entitativity. But it does not confirm our hypothesis that ingroup, even if perceived as more variable, should be perceived as more entitative, than outgroup. It may be due to the fact that the intergroup context was not salient enough to activate an ingroupoutgroup categorization. This should explain why, contrary to self-categorization theory, giving participants a comparative group did not allow a better intergroup differentiation.

Finally, Study 3 showed that interaction between favorability and extremity was significant only when target groups were low homogeneous groups composed of law students. Knowing that these students are associated with well-defined opinions and nomicity, it suggests that favorability and extremity are processed as interdependent cues only when information about homogeneity is inconsistent with expectations about nomicity. Otherwise, favorability and extremity are processed as additive cues for perceived entitativity.

In conclusion, these studies are in line with our argument that perceived entitativity of social groups does not depend only on their structural properties (extremity and homogeneity), but also on the context (here, an attitudinal one) where these properties are activated.

Future research should activate more explicit intergroup comparisons, and enrich the paradigm by giving content to attitudinal dimensions on which the entitativity judgments are based. This should allow taking into account not only own participants' positions but also expectations about the normative position and nomicity of the group under judgment.

It should also examine the consequences of the perceived entitativity of an opinion group on its evaluation, and on its credibility and expected influence.

\section{Notes}

1. A previous unpublished study (Allag, 1998) defined three types of distributions by manipulating the mode's position relative to the mean's: both positions were either the same (symmetrical), or different (asymmetrical). In the case of asymmetry, the mode was either left (leftskewed) or right (right-skewed) to the mean. Results showed that the form of the distribution had no effect and did not interact with variability.

2. In a study designed to illustrate the black sheep effect, a pre-test confirmed that psychology students displayed ingroup favoritism, by rating law students higher on negative traits, and lower on positive traits, than their own group.

3. Psychology (19) and law (18) students were asked to rate both groups on a 7-point overall similarity scale. Data displayed an interaction between participant and target group $(F(1,35)=7.17, p<$ $\left..05, \eta^{2}=.17\right)$, showing that outgroups were rated as more homogeneous $(M=3.61)$ than ingroups $(M=4.68)$.

4. I would like to thank an anonymous reviewer for this suggestion. 


\section{Acknowledgements}

I would like to thank Craig McGarty (University of Canberra, Australia), Dominique Oberlé (University of Paris X, France), and three anonymous reviewers for their helpful comments and constructive criticisms.

\section{References}

Allag, F. (1998). Entitativité et traitement de l'information. Unpublished manuscript.

Brewer, M. B., \& Harasty, A. S. (1996). Seeing groups as entities: The role of perceiver motivation. In R. M. Sorrentino \& E. T. Higgins (Eds.), Handbook of motivation and cognition (Vol. 3., pp. 347-370). New York: Guilford.

Campbell, D. T. (1958). Common fate, similarity, and other indices of the status of aggregates of persons as social entities. Behavioural Sciences, 3, 14-25.

Dasgupta, B., Banaji, M. R., \& Abelson, R. P. (1999). Group entitativity and group perception: Associations between physical features and psychological judgment. Journal of Personality and Social Psychology, 77, 991-1003.

Eagly, A. H., \& Carli, L. L. (1981). Sex of researchers and sex-typed communications as determinants of sex differences in influenceability: A meta-analysis of social influence studies. Psychological Bulletin, 90, $1-20$.

Hamilton, D. L., \& Sherman, S. J. (1996). Perceiving persons and groups. Psychological Review, 103, 336-355.

Hamilton, D. L., \& Zanna, M. P. (1972). Differential weighting of favorable and unfavorable attributes in impressions of personality. Journal of Experimental Research in Personality, 6, 204-212.

Harkins, S. G., \& Petty, R. E. (1987). Informational utility and the multiple source effect. Journal of Personality and Social Psychology, 52, 260-268.

Hong, Y-y, Levy, S. R., \& Chiu, C-y (2001). The contribution of lay theories approach to the study of groups. Personality and Social Psychology Review, 5, 98-106.

Lickel, B., Hamilton, D. L., Lewis, A., Sherman, S. J., Wieczorkowska, G., \& Neville Uhles, A. (2000). Varieties of groups and the perception of group entitativity. Journal of Personality and Social Psychology, 78, 223-246.

Lickel, B., Hamilton, D. L., \& Sherman, S. J. (2001). Elements of lay theory of groups: Types of groups, relational styles, and the perception of group entitativity. Personality and Social Psychology Review, 5, 129-140.
Maslach, C., Santee, R. T., \& Wade, C. (1987). Individuation, gender roles and dissent: Personality mediators of situational forces. Journal of Personality and Social Psychology, 53, 1088-1093.

McGarty, C., Haslam, S. A., Hutchinson, K. J., \& Grace, D. M. (1995). Determinants of perceived consistency: The relationship between group entitativity and the meaningfulness of categories. British Journal of Social Psychology, 34, 237-256.

Morchain, P., \& Schadron, G. (1999). Stéréotypisation et jugeabilité. Comment l'entitativité permet l'extrêmisation des jugements concernant les groupes défavorisés. Revue Internationale de Psychologie Sociale, 12, 25-46.

Moscovici, S. (1976). Social influence and social change London: Academic Press.

Mucchi-Faïna, A. (1996). Minority influence and gender influence. Unpublished manuscript.

Mullen, B. (1991). Group composition, salience and cognitive representations: The phenomenology of being in a group. Journal of Experimental Social Psychology, 27, 291-323.

Oberlé, D. (1996). Est-ce que le groupe intéresse toujours les psychologues sociaux? Connexions, 68 , 29-53.

Sherif, M., \& Sherif, C. W. (1967). Attitudes as the individual's own categories: The social judgment approach to attitude change. In C. W. Sherif, \& M. Sherif (Eds.), Attitude, ego involvment, and change (pp. 105-139). New York: Wiley.

Sherman, S. J., Hamilton, D. L., \& Lewis, A. C. (2000). Perceived entitativity and social identity value of group memberships. In D. Abrams \& M. Hogg. (Eds.), Social identity and social cognition (pp 80-110). Malde: MA: Blackwell.

Skowronski, J. J., \& Carlston, D. E. (1989). Negativity and extremity biases in impression formation: A review of explanations. Psychological Bulletin, 105, 131-142.

Steiner, I. D. (1974). Whatever happened to the group in social psychology? Journal of Experimental Social Psychology, 10, 94-108.

Susskind, J., Maurer, K., Thakkar, V., Hamilton, D. \& Sherman, J. (1999). Perceiving individuals and groups: Expectancies, dispositional inferences, and causal attributions. Journal of Personality and Social Psychology, 76, 181-191.

Wilder, D. A. (1977). Perception of groups, size of opposition, and social influence. Journal of Experimental Social Psychology, 13, 253-268.

Wilder, D. A. (1990). Some determinants of the persuasive power of ingroups and outgroups: Organization of information and attribution of 
independence. Journal of Personality and Social Psychology, 59, 1202-1213.

Wilder, D. A., \& Simon, D. A. (1998). Categorical and dynamic groups: Implications for social perception and intergroup behavior. In C. Sedikides, J. Schopler, \& C. A. Insko (Eds.), Intergroup cognition and intergroup behavior (pp. 27-44). Mahwah, NJ: Erlbaum.

Paper received 6 March 2003; revised version accepted 22 July 2004.

\section{Biographical note}

FRANCSOISE ASKEVIS-LEHERPEUX is a full professor of social psychology at the University of Lille III, France. Her current research interests are lay theories of groups, person memory, and relations between ingroup dynamics and outgroup perception. 